\title{
MONITORING INTERFACES FOR PHOTOVOLTAIC SYSTEMS AND DC MICROGRIDS: BRIEF SURVEY AND APPLICATION CASE
}

Isaías González Pérez, Antonio José Calderón Godoy, José María Portalo Calero, Manuel Calderón Godoy

Escuela de Ingenierías Industriales, Universidad de Extremadura, \{igonzp, ajcalde, calgodoy $\} @$ unex.es

\begin{abstract}
Monitoring interfaces enable the interaction between the human operator and the monitored process. This role acquires special relevance for advanced scenarios like microgrids and renewable energiesbased facilities, which involve a large amount of magnitudes and energetic interactions. This paper performs a brief survey about monitoring interfaces applied to DC microgrids and photovoltaic systems. The software environments that are used and graphical design aspects are studied and reported. Furthermore, an experimental case applying an open-source suite (Grafana) to a DC microgrid is expounded.
\end{abstract}

Keywords: Monitoring, renewable energy, microgrid, photovoltaics, open-source, Grafana.

\section{INTRODUCTION}

Microgrids constitute small-scale intelligent energy grids combining distributed generation and management. To achieve autonomous and efficient operation, microgrids are equipped with a number of sensors, actuators, controllers and monitoring systems. In addition, microgrids commonly incorporate renewable energies in order to implement environmental-friendly facilities. In fact, microgrids show a great potential to increase the penetration of renewable energies [30]. In this sense, photovoltaic generation is a mature technology able to be integrated within microgrids with different size and configurations.

To provide a reliable and stable power supply, a control and monitoring system is needed to deal with the variability and uncertainty of renewable energies [9]. Monitoring and supervisory systems are signaled as an essential infrastructure to evolve towards an energy system based on decentralized generation [26]. Even more, deploying distributed monitoring and control systems is one of the main challenges in the Smart Grid scope [6].
A monitoring interface displays real-time data to the operator in order to inform about the microgrid operation. Information of the main magnitudes of the microgrid components are shown through numerical and graphical resources. Command sending and data logging are tasks also supported by monitoring systems. A Data Acquisition System (DAS) is required, being composed by a hardware board devoted to gather signals from sensors/actuators mounted in the microgrid. Figure 1 depicts the described general configuration for a microgrid.

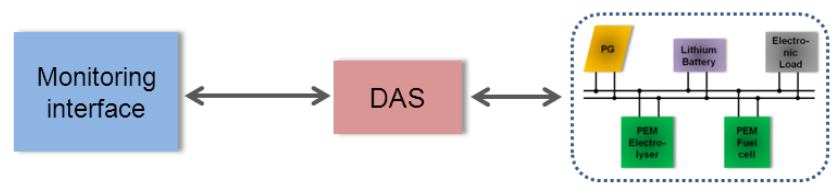

Figure 1: Block diagram of monitoring system applied to microgrid.

In this regard, an unstoppable trend consists on using open-source software and hardware to implement monitoring tasks. Low-cost, deep configurability and shared knowledge in the Internet are advantages associated to this type of technology. For instance, web-enabled platforms like Grafana [13], Thinger.io [15] and Angular [14] are used for monitoring tasks. About hardware resources, platforms for rapid electronics prototyping like Arduino [16], a microcontroller-based board, and the microcomputer Raspberry Pi [17] are widely applied in a large number of scenarios [2, 4].

Despite the importance of the monitoring function in these infrastructures, there is scarce literature about the design and deployment of this type of interfaces. A valuable recent paper that reviews and evaluates different visualization methods used in Smart Grids is found in [24]. Such research highlights the key role of visualization to facilitate monitoring and analyzing tasks in intelligent power grids.

This paper performs a brief literature survey about monitoring interfaces applied to photovoltaic systems and DC microgrids. The aim of this work is to 
provide an overview about the available monitoring software considering both proprietary and opensource options according to existing literature. Moreover, an application case of open-source software (Grafana) concerning a microgrid is expounded. Such a microgrid is framed in a $R \& D$ project about the development of digital replicas of smart microgrids based on renewable energies.

The structure of the rest of the article is as follows. The second section delivers an overview of the existing literature. In the third section, a set of design considerations for monitoring interfaces in microgrids are provided. Section 4 reports an opensource monitoring interface applied to a DC microgrid. Finally, the main conclusions of the conducted work are addressed.

\section{BRIEF LITERATURE SURVEY}

This section performs a literature survey about monitoring interfaces devoted to DC microgrids and photovoltaic systems. It must be noted that this work is not envisioned to present an in-depth review about monitoring systems for renewable energy-based facilities. As it has been previously indicated, the focus of this paper is solely put on photovoltaic systems and DC microgrids. There are very interesting works dealing with monitoring interfaces applied to AC microgrids as well as to hybrid power systems without photovoltaic generation; however, they have not been included in this survey.

In these scopes, a common practice consists on using software suites oriented to monitor/supervise industrial processes given their demonstrated reliability. Relevant examples are LabVIEW of National Instruments, WinCC of Siemens, and iFix of General Electric.

Another option is developing the interface with opensource software devoted to monitoring tasks, like $\mathrm{ScadaBr}$, TangoControls or Grafana. These packages decrease or eliminate expenditures but require lowlevel configurations and higher programming expertise. Further considerations about both options can be found in $[2,11,23,28]$.

Through diverse search processes in scientific databases, a set of papers from journals and conferences have been reviewed and selected. In order to provide useful and summarized information, Table I has been elaborated. As it can be seen, the scope of application, the used monitoring software, and the inclusion of scheme/diagrams and time-series plots are indicated. In some cases, in the managed paper there is no image of the developed interface so it is not known the type of implemented graphical representations. This situation is indicated in the table with NA (Not Available).

Table 1: Surveyed works and main features.

\begin{tabular}{|c|c|c|c|c|}
\hline Work & Scope & $\begin{array}{c}\text { Monitoring } \\
\text { software }\end{array}$ & $\begin{array}{l}\text { Scheme/ } \\
\text { Diagram }\end{array}$ & $\begin{array}{c}\text { Time- } \\
\text { series } \\
\text { plot }\end{array}$ \\
\hline [1] & $\begin{array}{l}\text { Photovolt } \\
\text { aics }\end{array}$ & Thinger.io & No & Yes \\
\hline [3] & Microgrid & LabVIEW & No & Yes \\
\hline [5] & Microgrid & LabVIEW & No & Yes \\
\hline [7] & Microgrid & WinCC & No & $\mathrm{No}$ \\
\hline [8] & Microgrid & LabVIEW & No & Yes \\
\hline [9] & Microgrid & WinCC & No & Yes \\
\hline [10] & Microgrid & EJS & Yes & Yes \\
\hline [12] & $\begin{array}{l}\text { Photovolt } \\
\text { aics }\end{array}$ & LabVIEW & No & Yes \\
\hline [19] & $\begin{array}{l}\text { Photovolt } \\
\text { aics }\end{array}$ & LabVIEW & No & No \\
\hline [20] & $\begin{array}{l}\text { Photovolt } \\
\text { aics }\end{array}$ & LabVIEW & Yes & Yes \\
\hline [21] & $\begin{array}{l}\text { Photovolt } \\
\text { aics }\end{array}$ & emonCMS & No & Yes \\
\hline [22] & $\begin{array}{l}\text { Photovolt } \\
\text { aics }\end{array}$ & PHP & No & Yes \\
\hline [25] & Microgrid & LabVIEW & Yes & No \\
\hline [27] & Microgrid & HTML5 & NA & NA \\
\hline [29] & $\begin{array}{l}\text { Photovolt } \\
\text { aics }\end{array}$ & Grafana & No & Yes \\
\hline [31] & Microgrid & iFix & Yes & No \\
\hline [32] & Microgrid & iFix & Yes & No \\
\hline
\end{tabular}

On the view of the conducted survey, the following conclusions can be delivered. To begin with, concerning the applied software environment for monitoring, Figure 2 illustrates graphically the percentage of usage of the evaluated packages. As can be observed, LabVIEW is the most used package, a fact also pointed out by other works [22]. On the other hand, open-source software is a serious trend, with a growing amount of applications in the considered scopes.

Regarding the hardware where the monitoring environment runs, it is a PC in the majority of systems. Nonetheless, open-source interfaces are usually executed in open-source hardware, mainly the microcomputer Raspberry Pi. About the style of the interface layout, a noticeably difference resides in the inclusion of schemes or diagrams of the monitored system. Only 5 of the reviewed contributions include a graphical representation of the physical system, commonly with a schematic 
approach. Moreover, time-series charts are included in almost all the surveyed works, witnessing that these plots are essential for proper monitoring interfaces.

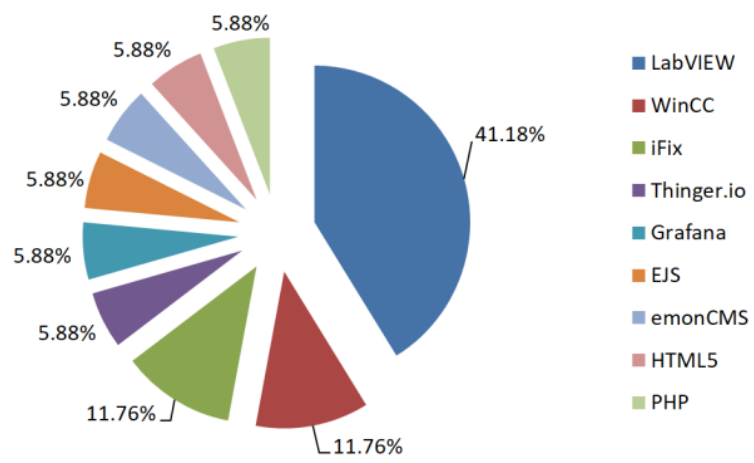

Figure 2: Percentage of usage of monitoring software in the surveyed works

\section{DESIGN CONSIDERATIONS}

This section contains a set of design considerations from the authors derived from the acquired expertise concerning monitoring systems applied to microgrids. Indeed, many of the commented aspects are also valid for monitored processes out of the energy scope.

Remote access to the monitoring system must be allowed. Nowadays, given the deep degree of penetration of Information and Communication Technologies (ICT), a monitoring interface must support on-line connections for tracking the microgrid at any moment from any place. In this regard, it must be noted that open-source solutions include by default this option, facilitating the remote visualization. On the other hand, proprietary solutions are increasingly providing apps for direct connection using smartphones. For example, the manufacturer of power equipment Victron Energy [18] offers an app to visualize the most relevant variables of the facilities involving its equipment, also accessible via web browser.

Another aspect is related to the schematic or synoptic representation of the monitored grid. The inclusion of synoptic diagrams facilitates the comprehension of the physical deployment of the microgrid. In addition, arrows or moving elements can be used to indicate the direction of the energy/hydrogen flow (from the bus to loads or from generators to the bus). Another option consists on modifying the colour of the connection lines in order to illustrate the direction changes.
A similar consideration for enhancing the humanmachine interaction consists on representing the physical device by means of illustrative draws or photography instead of through general block diagrams. Thus, the user/operator perceives the nature of the physical equipment in a high degree.

An interesting decision is about using screens or tabs dedicated to subsystems with enhanced information. For instance, an overview of the core system parameters and magnitudes within the main screen, as well as particular screens for detailed numerical and graphical data of a component (load or generator). With this layout, the user rapidly views the most illustrative information at a glance and, also, search for particular data if interested.

Information about the communication network that links the hardware for data acquisition and the equipment where the monitoring interface runs is also relevant. Data about the successful connection from nodes in the network or crash events can be useful for monitoring the proper operation of the information exchange. This data can be provided in dedicated screens jointly with other information like alarms.

Weather information is commonly added to the provided data in order to illustrate the existing conditions, which, evidently, affect to the power generation. For instance, high wind speed reduces the temperature of photovoltaic modules, improving their performance.

User administration is also a general function of monitoring systems. By means of user authentication (name and password) a basic level of security is implemented. Different degrees of access and permissions should be established in order to differentiate from simple observers to advanced administrators of the microgrid. Additional information security measures must be taking into account given the increasing cyber-security threats. Nevertheless, these issues are out of the scope of this paper.

In the case of enabled connection/disconnection of equipment, for instance, a load, buttons or similar controls are given for the user to manipulate the device from the interface. A similar option consists on modifying setpoints through numerical fields, so the operator can directly write a value which is sent in real-time to the memory of the controller. When these manipulations are enabled, restrictive check loops must be implemented in order to avoid erroneous values which could damage the equipment. This issue is related to the user administration commented in the previous point. 
Options provided to the operator can also be the selection of the storage file/database, the amount of magnitudes to include within a chart or even the time interval to visualize. In this regard, for graphical evolution over time of magnitudes, the considered interval is an important issue that can depend on the nature of such magnitude. For example, the variation of irradiance is generally slower than that of battery current. If the user can select the time interval, he/she is allowed to explore in real-time the behaviour over certain period. If this capability is not implemented, the operator will have to use the stored historical data.

The inclination degrees are not commonly shown in the interfaces, mainly due to the fact that the PV modules are fixed. In the case of tracking, to one or two axis, the interface should include this essential value.

Depending on the size of the facility, including geographical information in the form of GIS can be considered. In the case of DC microgrids, this information is not commonly provided.

Alarms and events are paramount requirements for any monitoring software. This feature is commonly included in the suites so the developer must configure thresholds and ranges over the monitored magnitudes in order to create alarms for anomalous situations or deviations of the expected behaviour.

Finally, an important requirement is that the software supports connectivity with open-source hardware and software. For example, LabVIEW can be connected to Arduino boards through the LIFA toolkit; Grafana can retrieve data from a large amount of database management systems like MariaDB, InfluxDB, PostgreSQL, etc. Besides, this connectivity can be achieved through open communication protocols like Open Platform Communications (OPC) or Modbus, widely incorporated in monitoring/supervisory software and also supported by open-source libraries. This characteristic is achieving increasing importance due to the aforesaid application of open-source technologies both for data acquisition and monitoring. Indeed, integration of commercial equipment with open-source tools also constitutes a prolific field of research within this scenario $[8,11]$.

\section{APPLICATION CASE USING OPEN-SOURCE SOFTWARE IN DC MICROGRID}

As indicated in the Introduction, within $R \& D$ context, a DC microgrid has been built with the corresponding monitoring interface. In this section, the key features of the microgrid as well as the deployed interface are described.

\subsection{DESCRIPTION OF THE DC MICROGRID}

The DC microgrid integrates renewable generation through a Photovoltaic Generator (PG), a Lithium battery for energy storage and hydrogen. For hydrogen production a Polymer Exchange Membrane (PEM) electrolyser is used, whereas a PEM fuel cell consumes the accumulated hydrogen to supply the load. Such load is a programmable equipment in order to configure different load profiles and test the operation of the facility. An automation system collects data from a variety of sensors and implements an energy management strategy for a proper behaviour. Figure 3 shows the schematic diagram of the microgrid.

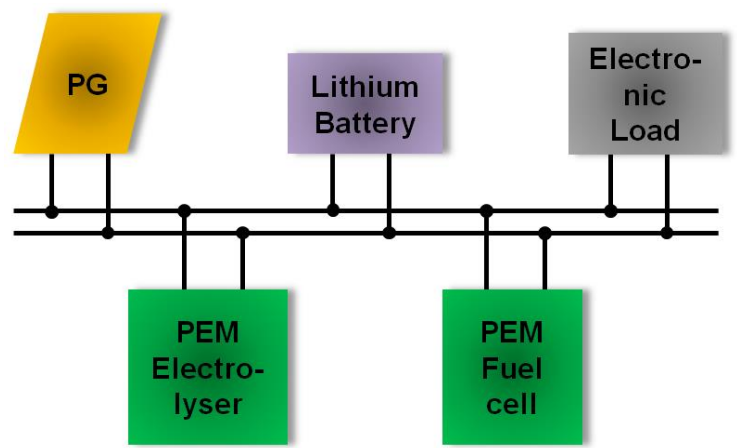

Figure 3: Diagram of the monitored DC microgrid.

\subsection{MONITORING INTERFACE USING OPEN-SOURCE GRAFANA}

In order to visualize in real-time the temperature of the modules that compose the PG, a monitoring interface has been implemented using Grafana. This software runs in a Raspberry Pi connected to an Arduino through an Ethernet network (see Figure 4). A set of digital sensors measure the temperature and send data to the Arduino, which transmits it to a database hosted by the Raspberry Pi. The Grafana dashboard collects this information and displays it in a friendly-manner to the user, which has established an on-line connection via web browser.

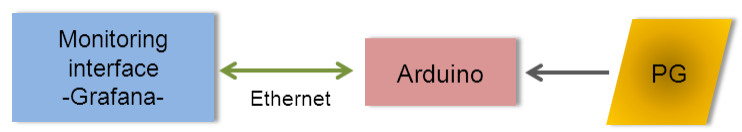

Figure 4: Deployed monitoring system using Grafana package.

The monitoring interface can be seen in Figure 5. It is composed by a time-series plot for the operator to observe the evolution of the sensed temperatures. 
The shown data corresponds to 10 and 11 February, being the first one a sunny day, so the measured temperatures evolve following the typical variation of irradiance. The user is able to zoom in the plot as well as to choose the time interval to visualize. In addition, a gauge illustrates the instant value of one temperature in order to know at a glance such value. Other element that has been considered relevant is a table which provides metrics, namely, the current, minimum and maximum temperatures for each sensor.

Designing dashboards with Grafana is an easy task mainly due to the wide variety of in-built functions and available add-ons. Consequently, intuitive and attractive graphics can be deployed without long development times neither programming skills.

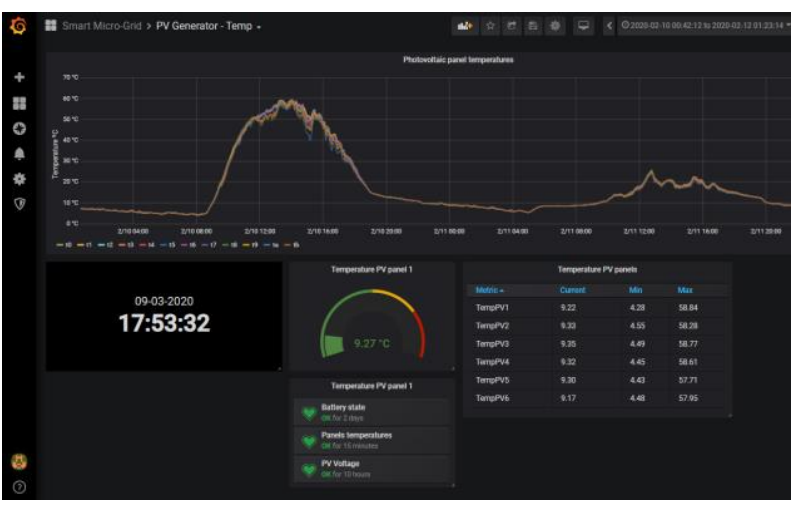

Figure 5: Monitoring interface developed to display the temperatures of PV modules in Grafana.

In addition, it must be remarked that the developed interface has been working in a continuous manner for 10 months without any crash event, which implies a reliable and stable operation. This interface is currently being enriched and expanded aiming to represent other variables of the microgrid.

Nonetheless, some disadvantages must be also commented. Namely, despite the fact that using Grafana is user-friendly, managing the RPi where it runs involves certain skills with the UNIX-based operating systems. This issue can be solved if MS Windows operating system was used, for which there are Grafana versions available.

On the other hand, Grafana does not allow manipulating the monitored process. This task is very useful for situations where the operator needs to modify some setpoint or parameter of the microgrid in a direct manner. To do this, writing operations should be performed over the memory positions of the control unit. However, as indicated, nowadays Grafana does not support this functionality.

\section{CONCLUSIONS}

The paper has presented a survey about monitoring interfaces applied to DC microgrids and photovoltaic systems. The main focus has been put on the software used as well as on deployment aspects. In addition, a set of design considerations have been provided. An application case using Grafana, opensource software, for an experimental microgrid has been described.

This work is envisioned to contribute to the design and development stage of monitoring interfaces devoted to microgrids within $R \& D$ projects.

Further guidelines will address the design of digital replicas of the microgrid using the information retrieved and stored by the reported monitoring interface.

\section{Acknowledgments}

This work has been supported by the FEDER Funds (Programa Operativo FEDER de Extremadura 20142020) through the grant "Ayuda a Grupos de Investigación” (ref. GR18159) of Junta de Extremadura.

\section{Resumen en español}

\section{INTERFACES DE MONITORIZACIÓN PARA MICROGRIDS Y SISTEMAS FOTOVOLTAICOS: BREVE REVISIÓN Y CASO DE APLICACIÓN}

\section{Resumen}

Los interfaces de monitorización permiten la interacción entre el operador humano y el proceso monitorizado. Esta función adquiere especial relevancia para escenarios avanzados como las microgrids y las instalaciones basadas en energías renovables, que integran una gran cantidad de magnitudes e interacciones energéticas. El presente artículo lleva a cabo una breve revisión sobre interfaces de monitorización aplicados a microgrids DC y sistemas fotovoltaicos. Los entornos software empleados así como aspectos sobre el diseño gráfico son estudiados y reportados. Además, se expone un caso de aplicación experimental utilizando software open-source (Grafana) en una microgrid DC.

Palabras clave: Monitorización, energías renovables, microgrid, energía fotovoltaica, opensource, Grafana. 


\section{References}

[1] Aghenta, L.O., Iqbal, M.T., (2019) "Low-Cost, Open Source IoT-Based SCADA System Design Using Thinger.IO and ESP32 Thing", Electronics, 8, 822.

[2] Calderón, A.J., González, I., Calderón, M., Segura, F., Andújar, J.M., (2016) "A New, Scalable and Low Cost Multi-Channel Monitoring System for Polymer Electrolyte Fuel Cells", Sensors, vol. 16(3), 349.

[3] Chinomi, N., Leelajindakrairerk, M., Boontaklang, S., Chompoo-Inwai, C., (2017) "Design and Implementation of a smart monitoring system of a modern renewable energy micro-grid system using a low-cost data acquisition system and LabVIEW program", Journal of International Council on Electrical Engineering, 7, 142-152.

[4] Costa, D.G., Duran-Faundez, C., (2018) “OpenSource Electronics Platforms as Enabling Technologies for Smart Cities: Recent Developments and Perspectives," Electronics, vol. 7, pp. 404.

[5] El-Leathey, L.A. (2018) "Energy Management System Designed for the Interconnected or Islanded Operation of a Microgrid Using LabVIEW Software," Book: Smart Microgrids, Chapter 3, IntechOpen.

[6] Ferreira, A., Ferreira, A., Cardin, O., Leitão, P., (2015) "Extension of holonic paradigm to smart grids", IFAC-PapersOnLine, vol. 48(3), pp. 1099-1104.

[7] Figueiredo J, Martins J., (2010) "Energy production system management - renewable energy power supply integration with building automation system", Energy Convers Manage, vol. 51(6), pp. 1120-6.

[8] González, I., Calderón, A.J., (2019) “Integration of open source hardware Arduino platform in automation systems applied to Smart Grids/Micro-Grids", Sustainable Energy Technologies and Assessments, vol. 36, 100557.

[9] González, I., Calderón, A.J., Calderón, M., Herrero, J.L., "Monitoring of Electric Power Systems: Application to self-sufficient Hybrid Renewable Energy Systems", Proceedings of the IEEE 9th International Conference on
Compatibility and Power Electronics (CPE), 2426 June 2015.

[10] González, I., Calderón, A.J., Andújar, J.M., (2017) "Novel Remote Monitoring Platform for RES-Hydrogen based Smart Microgrid", Energy Conversion and Management, vol. 148, pp. 489-505.

[11] González, I., Calderón, A.J., Portalo, J.M., (2021) "Innovative Multi-Layered Architecture for Heterogeneous Automation and Monitoring Systems: Application Case of a Photovoltaic Smart Microgrid", Sustainability, vol. 13(4), 2234.

[12] Hertzog, P., Swart, A.J., (2015) "The Use of an Innovative Jig to Stimulate Awareness of Sustainable Technologies among Freshman Engineering Students", Sustainability, 7, 91009117.

[13] https://grafana.com/

[14] https://opensource.google/projects/angular

[15] https://thinger.io/

[16] https://www.arduino.cc

[17] https://www.raspberrypi.org/

[18] https://www.victronenergy.com/

[19] Martínez, M.A., Andújar, J.M., Enrique, J.M., (2014) "Temperature Measurement in PV Facilities on a Per-Panel Scale," Sensors, vol. 14, pp. 13308-13323.

[20] Moreno-Garcia, I.M., Palacios-Garcia, E.J., Pallares-Lopez, V., Santiago, I., GonzalezRedondo, M.J., Varo-Martinez, M., Real-Calvo, R.J., (2016) Real-Time Monitoring System for a Utility-Scale Photovoltaic Power Plant. Sensors, vol. 16,770 .

[21] Paredes-Parra, J.M.; Mateo-Aroca, A., SilventeNiñirola, G., Bueso, M.C., Molina-García, Á., (2018) "PV Module Monitoring System Based on Low-Cost Solutions: Wireless Raspberry Application and Assessment", Energies, vol. 11,pp. 3051.

[22] Pereira, R.I.S., Dupont, I.M., Carvalho, P.C.M., Jucá, S.C.S., (2018) "IoT embedded linux system based on Raspberry Pi applied to realtime cloud monitoring of a decentralized photovoltaic plant", Measurement, vol. 114, pp. 286-297. 
[23] Portalo, J.M., González, I., Calderón, A.J., Calderón, M. Comparativa de entornos opensource para sistemas de supervisión aplicables a Smart Grids/Smart Micro-Grids. Proceedings of the XL Jornadas de Automática, Ferrol, September 2019.

[24] Sánchez-Hidalgo, M.A., Cano, M.D., (2018) “A survey on visual data representation for smart grids control and monitoring," Sustainable Energy, Grids and Networks, vol. 16, pp. 351369.

[25] Segura, F., Durán, E., Andújar, J.M., (2009) "Design, building and testing of a stand alone fuel cell hybrid system," Journal of Power Sources, vol. 193, pp. 276-284.

[26] Vale, Z., Morais, H., Faria, P., Ramos, C., (2013) "Distribution system operation supported by contextual energy resource management based on intelligent SCADA," Renewable Energy, vol. 52, pp. 143 - 153.

[27] Vargas-Salgado, C., Aguila-Leon, J., ChiñasPalacios, C., Hurtado-Pérez, E., (2019), "Lowcost web-based Supervisory Control and Data Acquisition system for a microgrid testbed: A case study in design and implementation for academic and research applications", Heliyon, vol. 5, e02474.

[28] Víctor, J.L.F., Jucá, S.C.S., Pereira, R.I.S., Carvalho, P.C.M., Fernández, L.M. IoT Monitoring systems applied to photovoltaic generation: The relevance for increasing decentralized plants. Proceedings of the 17th International Conference on Renewable Energies and Power Quality (ICREQP19), Spain, 10-12 April 2019.

[29] Voicu, V., Petreus, D., Etz, R. Data Acquisition System for Solar Panels. Proceedings of the 42nd International Spring Seminar on Electronics Technology (ISSE), Wroclaw, Poland, 15-19 May 2019.

[30] Zhang, L., Gari, N., Hmurcik, L.V., (2014) "Energy management in a microgrid with distributed energy resources", Energy Conversion and Management, vol. 78, pp. 297305.

[31] Ziogou, C., Giaouris, D., Papadopoulou, S. Voutetakis, S., (2016) "Supervisory Control and Monitoring of a Hybrid High Temperature PEM Fuel Cell System with Li-Ion Batteries and an
LPG Reformer," Chemical Engineering Transactions, vol. 52, pp. 1021-1026.

[32] Ziogou, C., Ipsakis, D., Elmasides, C., Stergiopoulos, F., Papadopoulou, S., Seferlis, P., Voutetakis, S., (2011) "Automation infrastructure and operation control strategy in a stand-alone power system based on renewable energy sources", Journal of Power Sources, vol. 196, pp. 9488-9499.

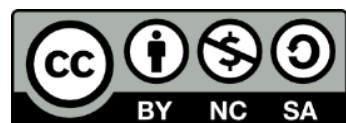

(C) 2021 by the authors. Submitted for possible open access publication under the terms and conditions of the Creative Commons Attribution CC BY-NC-SA 4.0 license (https://creativecommons.org/licenses/byncsa/4.0/deed.es). 